\title{
Characterization of Real Materials with Low Voltage STEM (30 kV): Current State and Challenges
}

Nicolas Brodusch and Raynald Gauvin

McGill University, Montreal, Quebec, Canada

Although low voltage scanning transmission electron microscopy (LV-STEM) was invented some 70-80 years ago, it has been rapidly put in competition with and surpassed by high energy STEMs and transmission electron microscopes (TEMs), essentially due to the increasing demand in spatial resolution [1]. In the late 90s, Merli and co-workers re-introduced LV-STEM through the production of simulated data on thin specimens in bright-field (BF) and dark-field (DF) modes which has led them to develop electron detectors adapted to this technology [2, 3]. This spectacular effort has led rapidly the manufacturers to invest in developing commercial LV-STEM and thus propose equipment proper to provide useful characterization tools at a resolution scale closer and closer to that obtained with the high voltage TEMs/STEMs. In this quest, the scanning electron microscope (SEM) was the foundation of a new standard in LV-STEM since SEM is already optimize for stable low voltage operation compared to high voltage equipment for which reducing the beam voltage is a serious challenge.

In addition to its lower cost, which is a fraction of the cost of its higher voltage counterpart, LV-STEM takes advantage of the relatively ease of use of the SEM technology as well as the increased scattering cross-sections leading to improved image contrast and signal collection. Figure 1 shows the increased interaction between the electron beam and the sample atoms in a $50 \mathrm{~nm}$ thin foil of amorphous boron nitride (BN) obtained by Monte Carlo modeling at an accelerating voltage of $200 \mathrm{kV}$ and $30 \mathrm{kV}$ with $10^{6}$ electron trajectories (red lines represent backscattered electrons). This increase in contrast thus allows producing high quality images from any material, provided its mass thickness is low enough to allow transmission signals to be collected. However, the quest for improving the spatial resolution by boosting the gun brightness in cold-field emission SEMs (CFE-SEM) led to increasingly high probe current density, intensifying the probability of knock-on (KO) and ionization damage in sensitive materials. The KO displacement events were tracked in the simulation of Figure 1 and are displayed as blue and green dots for boron and nitrogen atoms and it shows that low beam voltages helps reducing or even vanishing potential damage by knock-on processes since $\mathrm{KO}$ damage did not occur in $\mathrm{BN}$ at $30 \mathrm{kV}$.

In this presentation, it will be demonstrated how modern LV-SEM/STEM can provide high quality and useful characterization data in a scale range comparable to the higher resolution transmission microscopes. As an example, Figure 2 shows analytical results obtained with the Hitachi SU-9000 CFE-SEM/LV-STEM on a thin specimen of an AA2099 Al-Cu-Li alloy where lattice imaging of the fine $\delta^{\prime}\left(\mathrm{Al}_{3} \mathrm{Li}\right)$ is resolved (a-b) and an elemental $\mathrm{Cu} \mathrm{L}_{\mathrm{II} / \mathrm{III}}$ map obtained by the jump ratio method [4] with the corresponding HAADF image (c-d) where the $\mathrm{T} 1$ plates $\left(\mathrm{Al}_{2} \mathrm{CuLi}\right)$ are clearly evidenced. 

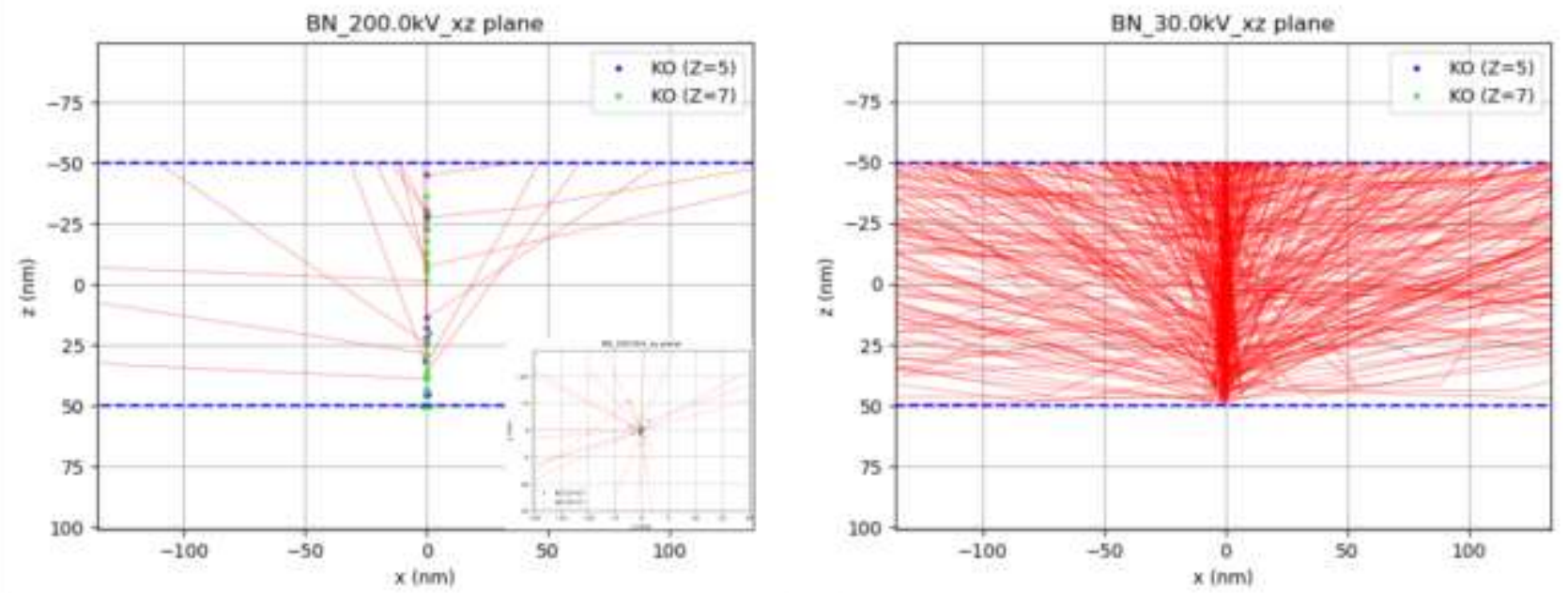

Figure 1. Monte Carlo simulations in an aluminum foil of $50 \mathrm{~nm}$ thickness at accelerating voltages of $200 \mathrm{kV}$ (left) and $30 \mathrm{kV}$ (right). Red lines show the BSE trajectories while the blue and green dots stand for knock-on displacements of boron and nitrogen along the electron path. 1 million trajectories where simulated to produce these graphs.
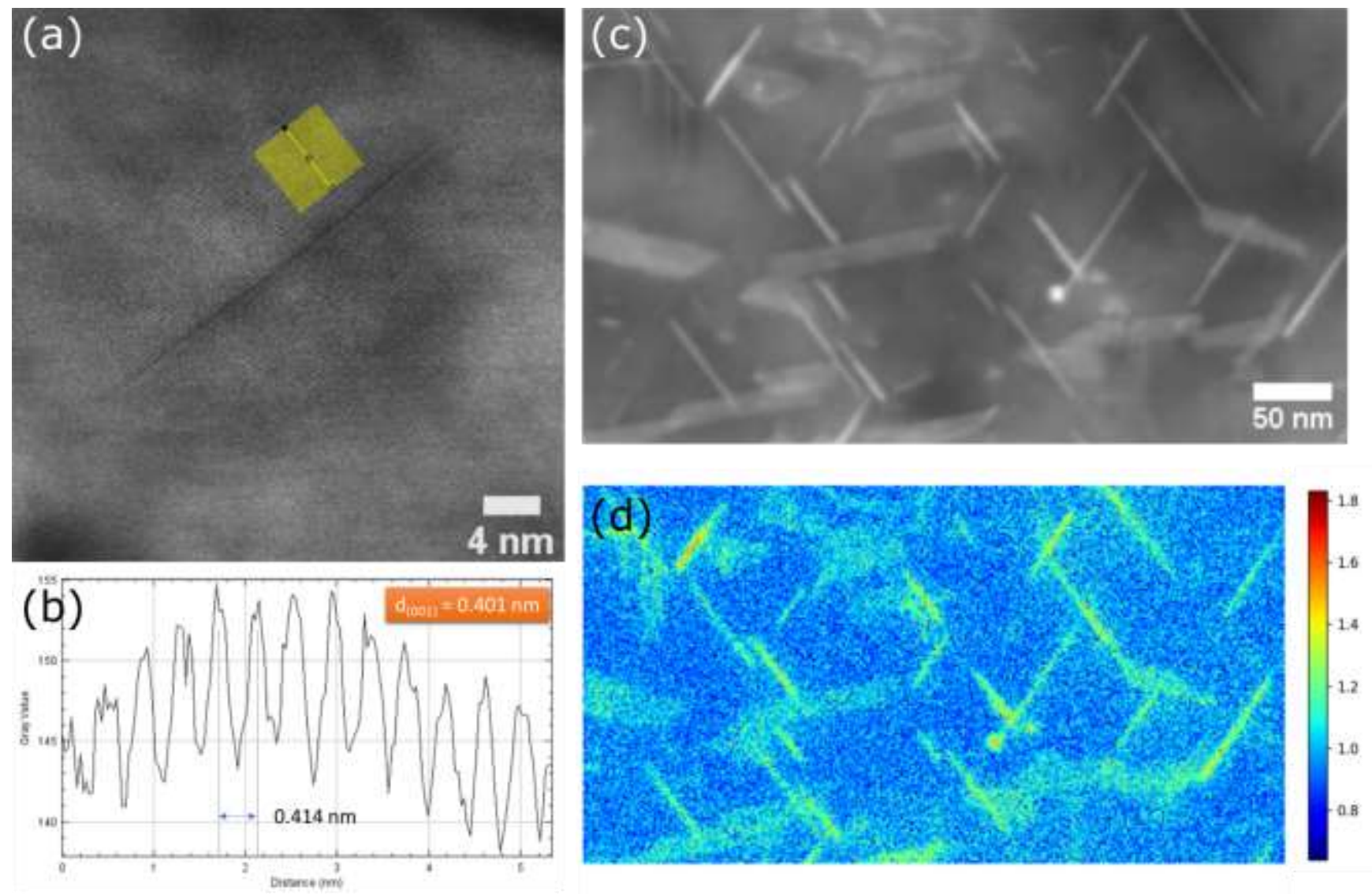

Figure 2. Analytical characterization of n AA2099 Al-Cu-Li alloy with a SU9000 CFE-SEM at $30 \mathrm{kV}$ : (a) Lattice bright-field image of $\delta$ ' a (Al3Li) precipitate with the lattice spacing measurement in (b); (c) HAADF image of the fine microstructure showing $\mathrm{T} 1(\mathrm{Al} 2 \mathrm{CuLi})$ precipitates and (d) experimental elemental map obtained with the jump ratio method by LV-EELS for Cu LII/III edge. 


\section{References}

[1] S.J. Pennycook, P.D. Nellist, Scanning transmission electron microscopy: imaging and analysis, Springer, 2011.

[2] P.G. Merli, A. Migliori, M. Nacucchi, M. Vittori Antisari, Comparison of spatial resolutions obtained with different signal components in scanning electron microscopy, Ultramicroscopy, 65 (1996) 23-30.

[3] P.G. Merli, F. Corticelli, V. Morandi, Images of dopant profiles in low-energy scanning transmission electron microscopy, Applied physics letters, 81 (2002) 4535-4537.

[4] R.F. Egerton, Electron Energy-Loss Spectroscopy in the Electron Microscope, Third ed., Springer, 2011 